\title{
Post-Processing of Cold Sprayed Ti-6Al-4V Coatings by Mechanical Peening
}

\author{
Niroj Maharjan ${ }^{1, *}$, Ayan Bhowmik ${ }^{2,3}$, Chunwai Kum ${ }^{1}$, Jiakun Hu ${ }^{1}$, Yongjing Yang ${ }^{2}$ and Wei Zhou ${ }^{2, *}$ (D) \\ 1 Data-Driven Surface Enhancement Team, Advanced Remanufacturing and Technology Centre, \\ 3 CleanTech Loop, Singapore 637143, Singapore; kumcw@artc.a-star.edu.sg (C.K.); \\ jeffrey_hu@artc.a-star.edu.sg (J.H.) \\ 2 School of Mechanical and Aerospace Engineering, Nanyang Technological University, 50 Nanyang Avenue, \\ Singapore 639798, Singapore; abhowmik@ntu.edu.sg (A.B.); yonging001@ntu.edu.sg (Y.Y.) \\ 3 Department of Materials Science and Engineering, Indian Institute of Technology Delhi, Hauz Khas, \\ New Delhi 110016, India \\ * Correspondence: maharjan_niroj@artc.a-star.edu.sg (N.M.); wzhou@cantab.net (W.Z.)
}

Citation: Maharjan, N.; Bhowmik,

A.; Kum, C.; Hu, J.; Yang, Y.; Zhou, W. Post-Processing of Cold Sprayed Ti-6Al-4V Coatings by Mechanical Peening. Metals 2021, 11, 1038. https://doi.org/10.3390/ met11071038

Academic Editor: Matteo Benedetti

Received: 5 June 2021

Accepted: 26 June 2021

Published: 29 June 2021

Publisher's Note: MDPI stays neutral with regard to jurisdictional claims in published maps and institutional affiliations.

Copyright: (C) 2021 by the authors. Licensee MDPI, Basel, Switzerland. This article is an open access article distributed under the terms and conditions of the Creative Commons Attribution (CC BY) license (https:// creativecommons.org/licenses/by/ $4.0 /)$.

\begin{abstract}
Cold spray is an emerging additive manufacturing technology used in the aerospace industry to repair damaged components made of expensive metal alloys. The cold sprayed layer is prone to surface integrity issues such as high porosity and inadequate bonding at the substratecoating interface, which may cause premature failure of the repaired component. This study explored the use of mechanical peening as a post-processing method to improve the surface integrity of the cold sprayed component by modifying mechanical properties near the surface. Two mechanical peening processes, deep cold rolling (DCR) and controlled hammer peening (CHP), were utilized to improve cold sprayed Ti-6Al-4V coating on the Ti-6Al-4V substrate. Experimental results indicate that DCR and CHP increase the strength of the bond between the coating and substrate due to introduction of compressive residual stresses. In addition, porosity is also reduced by as much as $71 \%$. The improvement is attributed to both the compacting effect of peening processes and the increment in the volume fraction of deformed regions.
\end{abstract}

Keywords: cold spray; deep cold rolling; controlled hammer peening; Ti-6Al-4V coating; surface integrity

\section{Introduction}

Cold spray or cold gas dynamic spray is a recently developed non-thermal all-solidstate additive manufacturing technique used for repair and restoration of metal components. It employs a high speed gas jet to accelerate metal powders towards a substrate where they adhere directly via metallurgical bonding or mechanical interlocking [1]. Compared to traditional repair processes such as welding and thermal spraying, the cold spray process is fast and produces minimal distortion or heat affected zone. Due to its benefits, it is currently implemented for dimensional restoration of components in aerospace, automotive and marine industries that experience wear and/or corrosion in service [2].

Repair of Ti-6Al-4V components, used in aircraft components, often requires material build-up to several millimeters thickness. This makes cold spray an ideal process for such applications because of its high deposition efficiency [3]. However, a recent review by Li et al. [4] highlights the challenges in producing dense titanium coatings with properties equivalent to bulk material due to its high strength in comparison to most commonly sprayed metals.

Studies have shown that surface integrity of the cold sprayed Ti-6Al-4V layer could be compromised by the presence of porosity, tensile residual stresses and weak adhesion between coating and substrate. Depending on the conditions used, porosity between $0.5 \%$ and $22 \%$ have been reported in the literature for Ti-6Al-4V coating. Li et al. [5] found a porosity level as high as $22 \%$ for the Ti- $6 \mathrm{Al}-4 \mathrm{~V}$ coating on the Ti-6Al-4V substrate. They 
reported that the pores were present mostly between deposited microparticles. Similarly, Vo et al. [6] reported a porosity of around 7\% for the Ti-6Al-4V coating. They were able to reduce the porosity level to lower than $1 \%$ using helium as the propellant gas. Furthermore, Tan et al. [7] reported a porosity level of only $3 \%$ for coating even with a thickness as large as $3 \mathrm{~mm}$. They also observed that coatings tend to have a higher porosity level near the top surface due to the absence of an impinging effect.

Bonding between the coating and substrate also influences the integrity of the cold spray layer. Investigation by Goldbaum et al. [8] revealed the presence of the discontinuous bond interface with only traces of metallurgical bonding despite very high deposition velocities of $1115 \mathrm{~m} / \mathrm{s}$. Moreover, the presence of tensile residual stresses promotes crack growth and delamination of the cold spray layer. Boruah et al. [9] evaluated the residual stresses induced by cold spraying of Ti-6Al-4V on the Ti-6Al-4V substrate using neutron diffraction and the contour method and found the presence of high tensile stresses near the free surface and in the substrate close to the interface. All this can eventually result in the premature failure of valuable cold sprayed components.

Various methods have been implemented to improve the quality of the cold spray for titanium alloy coatings. These can be broadly grouped into three categories-(a) surface preparation by roughening or blasting, (b) optimizing processing parameters and (c) post-annealing heat treatment. Sun et al. [10] investigated the effect of grinding, milling, blasting and water jet cutting a surface prior to cold spray and discovered that the coatings deposited on the ground surface had the longest fatigue life. This demonstrates that a correct surface preparation method improves the bonding between the substrate and coating at the interface. However, it cannot improve the quality of the coating itself. Similarly, it is possible to reduce the porosity and improve the integrity of the cold sprayed component by optimizing processing parameters [11] and changing the working gas from nitrogen to helium gas $[6,12]$. However, helium is much more expensive than nitrogen and the extent of improvement brought about by parameter optimization may be limited by the process fundamentals. More recently, the post-annealing heat treatment has also been shown to be effective in reducing pore size and increasing metallurgical bonding between deposited particles [13,14]. However, the heat treatment can alter the base microstructure as well and is often expensive and time consuming.

As an alternative, mechanical peening as a post-processing step could be beneficial in improving the surface integrity of cold sprayed components. The peening process induces plastic deformation and generates a compressive residual stress layer near the surface [15]. This could be advantageous in reducing porosity and improving bond strength of cold sprayed components. In addition, the peening allows precise localized processing of a component that could be beneficial to improve the integrity of a local region such as bends or corners without affecting other regions.

Very few investigations have been reported on the effect of peening on the cold spray layer with results still inconclusive. Fatigue evaluation of cold spray coatings with shot peening as both pre- and post-treatment by Moridi et al. [16] revealed that shot peening is more effective when it is performed prior to cold spray deposition. On the other hand, Luo et al. [17] recently reported a porosity reduction to values as low as $0.6 \%$ using "in-situ" shot peening assisted cold spraying by mixing large sized shot peening particles with spraying powders. This clearly exhibits the potential of peening on improving integrity of cold spray coating.

In this study, two mechanical peening methods, deep cold rolling (DCR) and controlled hammer peening (CHP), were utilized as post-processing techniques to improve the surface integrity of cold sprayed components. Typical peening conditions used in industry for inducing compressive residual stresses on components were employed for the study. The results show that both DCR and CHP are capable of reducing porosities and improving bond strength of cold sprayed components. 


\section{Materials and Methods}

\subsection{Material}

Ti-6Al-4V alloy (Grade 5) was used as the main material for the study. This alloy has excellent mechanical properties and is widely used in the aerospace industry. Coupons of size $50 \times 30 \times 10 \mathrm{~mm}^{3}$ were used as a substrate for the cold spray (see Figure 1a). The substrates were machined to an average surface roughness of about $8 \mu \mathrm{m}$ and cleaned prior to spraying. The powder feedstock used was plasma-atomized Ti-6Al-4V powder comprising primarily of spherical particles ranging from 3 to $90 \mu \mathrm{m}$ diameter (see Figure 1c,d).

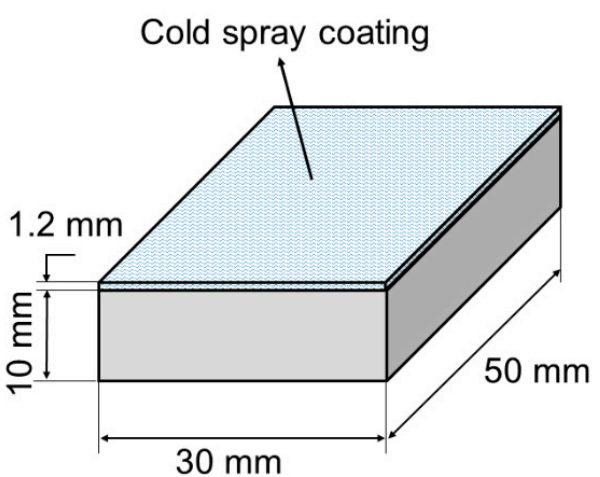

(a)

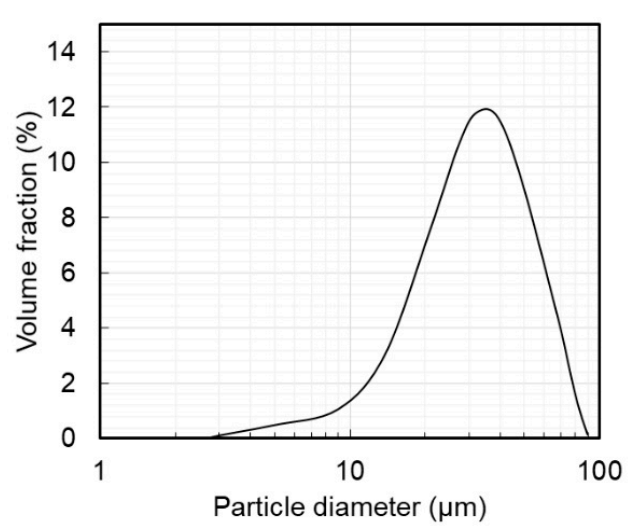

(c)

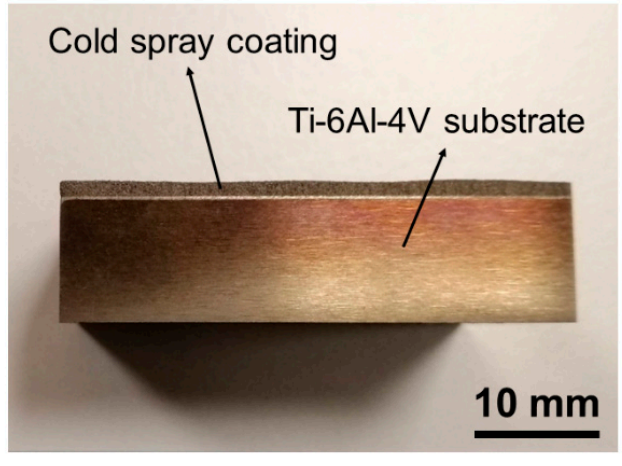

(b)

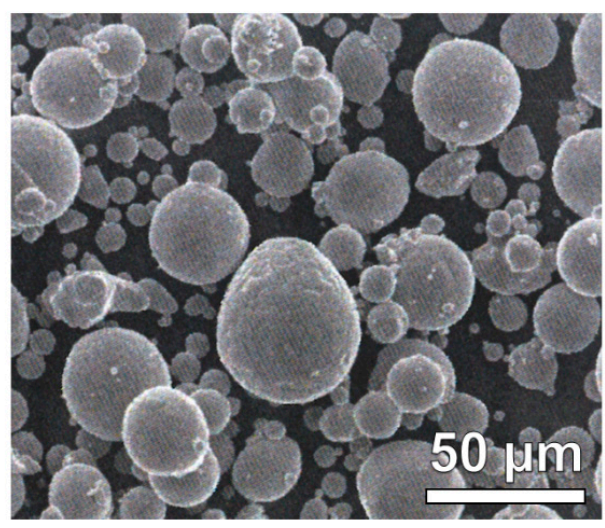

(d)

Figure 1. (a) Schematic of as-sprayed coupon; (b) cold-sprayed coupon; (c) cold spray particle size distribution; (d) particle morphology.

\subsection{Cold Spraying}

The Plasma Giken system (Cold Spray PCS 1000, Plasma, Saitama, Japan) was employed to deposit Ti-6Al-4V coatings on the Ti-6Al-4V substrate. The system used nitrogen as the working gas. Typical parameters for cold spraying was used and no optimization was performed. The gas was preheated to $1000{ }^{\circ} \mathrm{C}$ and blown across the De Laval (convergent-divergent) nozzle at $5 \mathrm{MPa}$ pressure to deposit the powders onto the substrate. A robot was used to raster scan the surface at $500 \mathrm{~mm} / \mathrm{s}$ and $0.5 \mathrm{~mm}$ step size. At such a condition, there is a limited heat transfer between the spray gas and the part, with the part heating up to $330^{\circ} \mathrm{C}$ maximum for a few seconds only [18]. Therefore, negligible surface oxidation was assumed prior to coating. The final coating thickness of the Ti-6Al-4V coating was around $1.2 \mathrm{~mm}$ with an average roughness of around $12.5 \mu \mathrm{m}$. The detailed process parameters are summarized in Table 1 and the cold sprayed coupon is shown in Figure 1. 
Table 1. Cold spray processing parameters.

\begin{tabular}{cc}
\hline Machine Used & Plasma Giken \\
\hline Working gas & Nitrogen \\
Gas Pressure & $5 \mathrm{MPa}$ \\
Gas Temperature & $1000{ }^{\circ} \mathrm{C}$ \\
Robot velocity (traverse speed) & $500 \mathrm{~mm} / \mathrm{s}$ \\
Spray angle & $90^{\circ}$ \\
Powder feed rate & $12 \mathrm{~g} / \mathrm{min}$ \\
Step size & $0.5 \mathrm{~mm}$ \\
Original powder size & $45 \mu \mathrm{m}(3-90 \mu \mathrm{m})$ \\
\hline
\end{tabular}

\subsection{Post-Peening Trials}

Two post-processing methods, deep cold rolling (DCR) and controlled hammer peening (CHP), were used in this study (see Figure 2). In order to ensure the uniformity, all cold sprayed coupons were machined down to approximately $0.6 \mathrm{~mm}$ thickness. The detailed processing parameters used for DCR and CHP are shown in Tables 2 and 3 respectively. A tungsten carbide ball was used in both processes. DCR was performed on a CNC machine for good control of the process. Only pressure was varied during the process with all other parameters kept constant. CHP trials were conducted using a standard hammer peening tool developed by Ecoroll, Germany, mounted on an industry robot. Two sets of peening conditions were selected: one with low values of peening conditions and the other with high peening conditions.

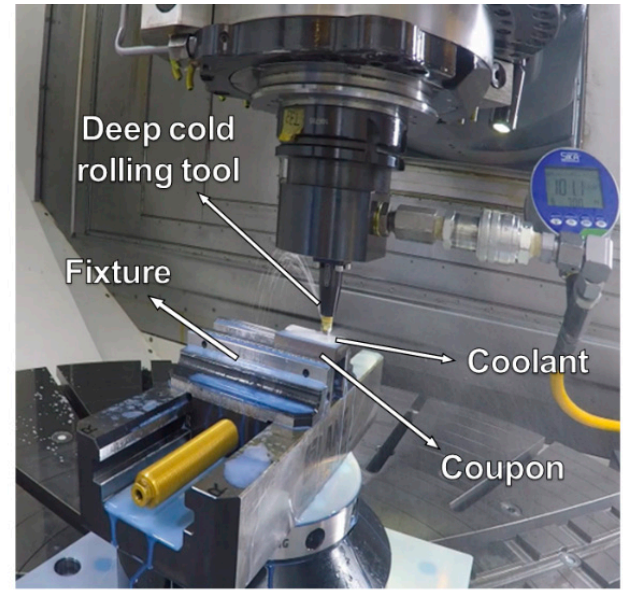

(a)

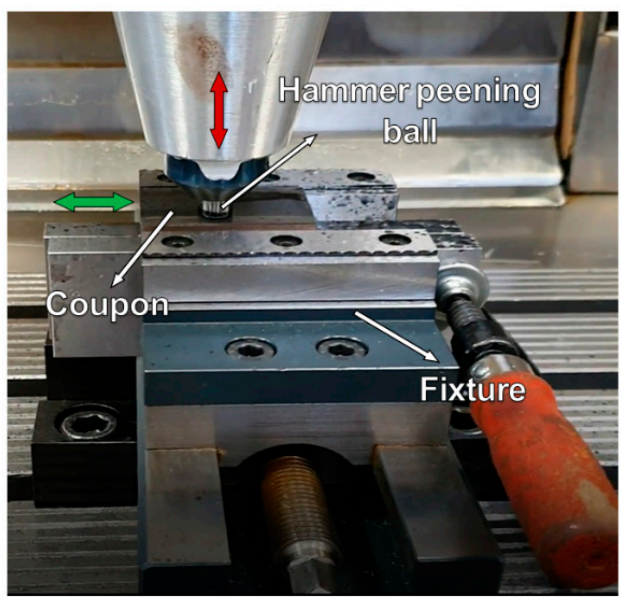

(b)

Figure 2. Images showing post-processing by (a) DCR (deep cold rolling) and (b) CHP (controlled hammer peening).

Table 2. Processing parameters used for deep cold rolling (DCR).

\begin{tabular}{ccccccc}
\hline Sample Code & Pressure (Bar) & Coverage & $\begin{array}{c}\text { Ball Size } \\
\boldsymbol{\sigma}(\mathbf{m m})\end{array}$ & $\begin{array}{c}\text { Feed Rate } \\
(\mathbf{m m} / \mathbf{m i n})\end{array}$ & $\begin{array}{c}\text { Average Track } \\
\text { Width (mm) }\end{array}$ & $\begin{array}{c}\text { Number of } \\
\text { Repeats }\end{array}$ \\
\hline DCR_low & 100 & $200 \%$ & 6 & 1000 & 0.16 & 3 \\
DCR_high & 300 & $200 \%$ & 6 & 1000 & 0.25 & 3 \\
\hline
\end{tabular}

\subsection{Characterization}

The average roughness of coupons was measured using a contact mode surface profilometer (PGI Talyscan, Taylor Hobson, Leicester, UK). For each coupon, at least three 
random line measurements were taken under the scan conditions of $10 \mathrm{~mm}$ length and scan step of $0.5 \mathrm{~mm} / \mathrm{s}$ and the average value was reported.

Table 3. Processing conditions used for controlled hammer peening (CHP).

\begin{tabular}{cccccccc}
\hline $\begin{array}{c}\text { Sample } \\
\text { Code }\end{array}$ & $\begin{array}{c}\text { Ball Size } \\
(\mathbf{m m})\end{array}$ & $\begin{array}{c}\text { Spindle Speed } \\
\text { (RPM) }\end{array}$ & $\begin{array}{c}\text { Frequency } \\
\text { (Hz) }\end{array}$ & $\begin{array}{c}\text { Feed Rate } \\
(\mathbf{m m} / \mathbf{m i n})\end{array}$ & $\begin{array}{c}\text { Step Size } \\
(\mathbf{m m})\end{array}$ & $\begin{array}{c}\text { Stand off Z+ } \\
(\mathbf{m m})\end{array}$ & $\begin{array}{c}\text { Number of } \\
\text { Repeats }\end{array}$ \\
\hline CHP_low & 8 & 800 & 80 & 500 & 0.1 & 1 & 3 \\
CHP_high & 50 & 1200 & 120 & 1500 & 0.2 & 1 & 3 \\
\hline
\end{tabular}

The residual stress measurements were carried out using the central hole drilling technique. The surfaces were prepared for type A strain gauge (Vishay Precision Group type EA-06-062RE-120) installation by light hand grinding using grade $400 \mathrm{SiC}$ paper. The surface was then cleaned with acetone and gauges were bonded using the Loctite 407 adhesive (Henkel, Düsseldorf, Germany). These gauges were installed with element 1 aligned along the longitudinal direction and element 3 along the transverse direction as shown in Figure 3a. The relaxed strains recorded using the gauge elements were used to calculate longitudinal and transverse residual stresses respectively using the integral method [19]. The orbital hole drilling procedure was carried out at 16 drill depth increments, recording the relaxed strains at each increment. Drilling depth increments were set at $(4 \times 32 \mu \mathrm{m})+(4 \times 64 \mu \mathrm{m})+(8 \times 128 \mu \mathrm{m})$ to give a completed hole depth of $1408 \mu \mathrm{m}$ for the measurement of stresses to a depth of $1024 \mu \mathrm{m}$ (see Figure 3).

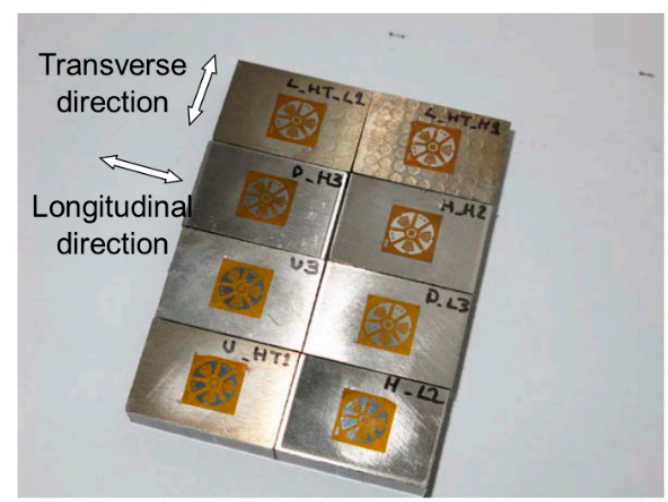

(a)

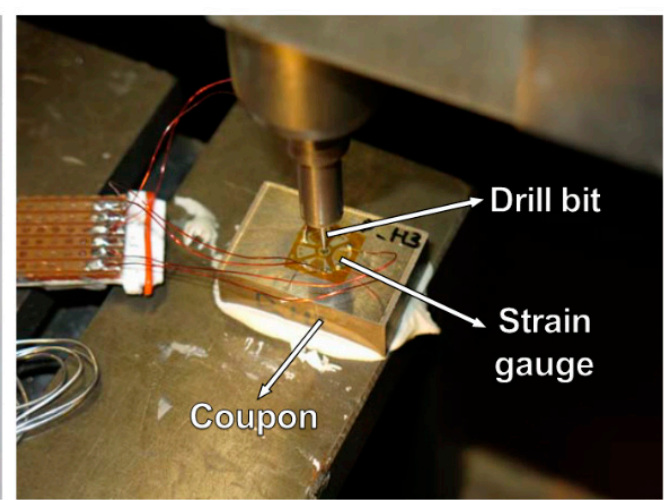

(b)

Figure 3. Images showing (a) strain gauge installation and (b) incremental hole drilling. The longitudinal and transverse directions are shown in (a).

For cross-section analysis, the coupons were sectioned using wire electric discharge machining. The cut coupons were then mounted, ground and polished following a standard sample preparation technique. Final polishing was performed using $0.04 \mu \mathrm{m}$ colloidal silica suspension, which produced a mirror-like finish. The polished surface was observed under the optical microscope (Olympus BX53M, Tokyo, Japan) and scanning electron microscope (SEM, JEOL JSM7600F, Tokyo, Japan). A computer software (Clemex Vision, Clemex Inc, Montreal, QC, Canada) was used to analyze the porosity level in the coating. At least five images at $100 \times$ magnification for each case were considered for the porosity evaluation.

Hardness measurements were performed on the polished surface using a Vickers indenter at a $100 \mathrm{gf}$ load and $10 \mathrm{~s}$ dwell time (Falcon 500, Innovatest, Maastricht, The Netherlands). The indents were made at predetermined intervals to capture the hardness variation along the depth. Similarly, X-ray diffraction (XRD) data was collected from the cold sprayed surface using Panalytical Empyrean XRD, Malvern, UK. The diffractometer used a copper target as a source of X-ray with wavelength $\lambda=1.5404 \AA(\mathrm{Cu} \mathrm{K} \alpha 1)$. 
The scanning angle was in the range of $60-68^{\circ}$ with a step size of $0.02^{\circ}$ and scan speed of $0.002^{\circ} / \mathrm{s}$.

The bond strength of the coupons was measured by performing an adhesive bond test following the ASTM C633-13 standard (see Figure 4). For this, the coupons were machined into circular buttons with a diameter of $25.4 \mathrm{~mm}$ and glued to the test fixtures using FM 1000 epoxy. The whole assembly was placed inside an oven to cure the epoxy. The assembly was then tested in a standard pull setup to observe the location of the failure and the load at which the failure would occur. Three repeats were performed for each condition. It is to be noted that the maximum bond strength that can be measured by this process is limited by the strength of the epoxy. If failure occurs at the epoxy, then the absolute bond strength of coating-substrate could not be calculated.
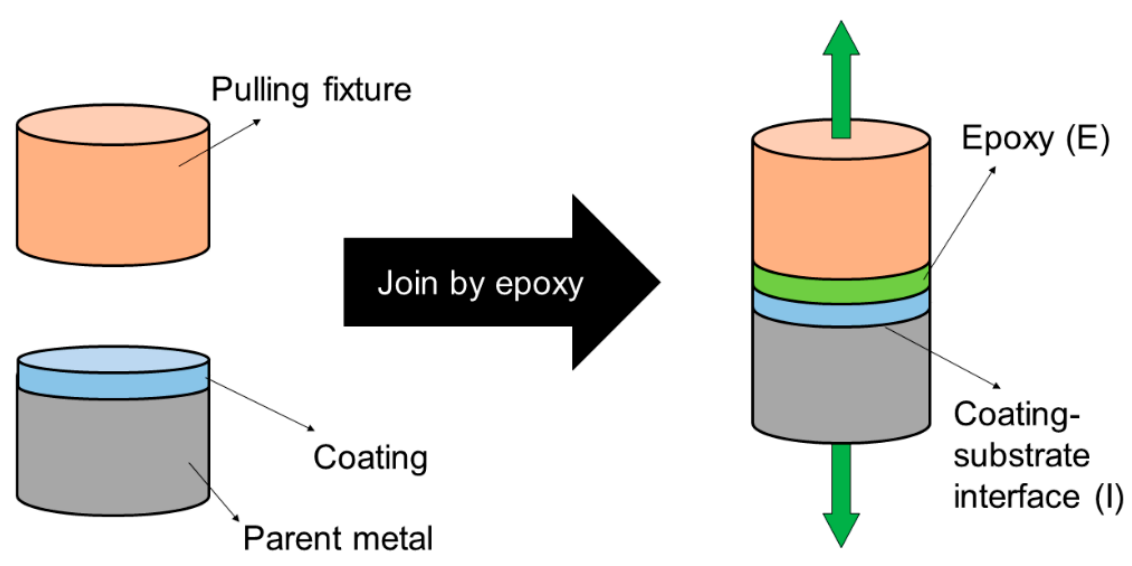

Figure 4. Setup for the adhesive bond test.

\section{Results}

\subsection{As-Sprayed Microstructure}

A typical cross-section microstructure of the cold sprayed coupon is shown in Figure 5. The coating layer contained numerous pores. Measurement of the pores using an optical microscope showed the average porosity varied from $8.5 \%$ to $10 \%$. Such high porosity coupons were deliberately used for the study to understand the effects of post-processing through mechanical peening. At higher magnification, undeformed powders could be observed inside some of the cavities (see Figure 5b). These powders might have remained unfused due to insufficient energy available during the cold spray process. Good bonding could be observed between the coating and the substrate as no visible crack or delamination was present at the interface.

Since the pores are detrimental to the mechanical integrity of the coating, postprocessing trials were performed with an aim to minimize the porosity. In addition, the bond strength and other properties of the coating might also be improved during post-processing. The results obtained from the various post-processing experiments are discussed in the following sections.

\subsection{Comparison of Mechanical Peening Processes}

\subsubsection{Surface Roughness}

Figure 6 compares the topography of surfaces under different conditions. The average roughness of the as-sprayed test coupons (after machining) was about $0.5 \mu \mathrm{m}$. The machining marks are clearly visible in Figure 6b. DCR processing smoothens the surface as can be seen from Figure $6 \mathrm{c}, \mathrm{d}$. The average roughness reduced to around $0.2 \mu \mathrm{m}$ after DCR. Under low DCR processing condition, some machining marks were still present. These marks were completely removed under high pressure DCR. In addition, light grooves could also be observed along the ball rolling direction due to plastic deformation. On the contrary, 
the CHP process was found to increase the average roughness (Figure 6e,f). The roughness values were higher at high peening conditions compared to low peening conditions.

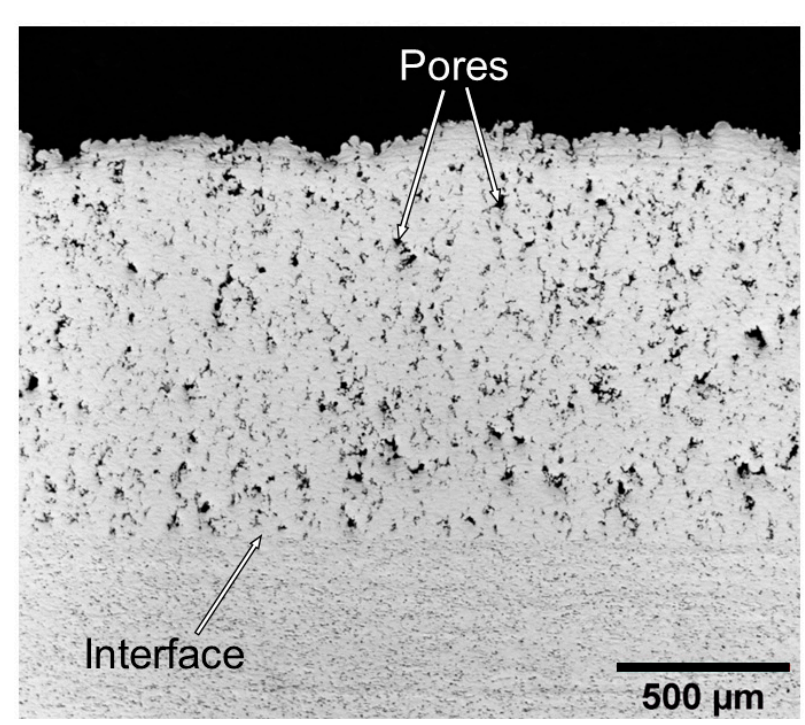

(a)

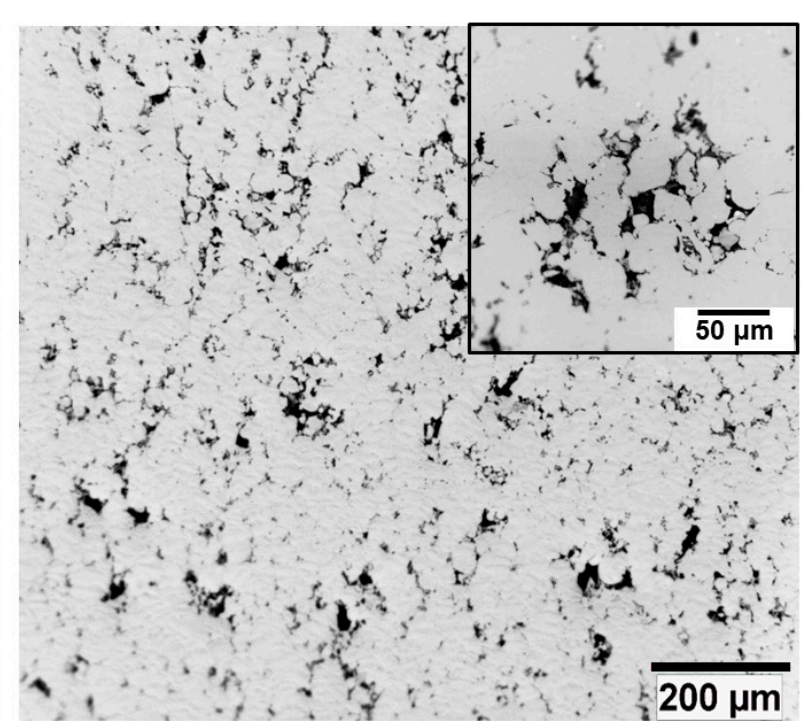

(b)

Figure 5. Cross-section micrograph of cold spray coating showing (a) overall coating layer and (b) magnified image with pores (inset shows some unfused powders).

DCR uses a hydrostatically controlled roller that produces a small amount of plastic deformation near the surface. The roller is moved along the surface to cover a large area that helps to smoothen the surface. On the other hand, CHP produces a peening effect by hammering with a spherical carbide tool. The hammering produces distinct peening dimples along the surface with the highest depth right below the center of the tool, leading to higher surface roughness. High peening condition produces larger dimples, leading to an even rougher surface.

\subsubsection{Residual Stresses}

Compressive residual stresses in the cold spray layer increases density and hardness of the coating [20]. Mechanical peening processes used in this study are known to increase the fatigue life of the component by inducing compressive residual stresses at the surface [21-23]. However, little investigation is done on the stress condition at the coating substrate interface after peening. The current study, therefore, used an incremental hole drilling method to measure residual stress state up to a depth of $1 \mathrm{~mm}$ from the surface.

Figure 7 compares the residual stress profile along the depth of test coupons under different post-processing conditions. In the as-sprayed condition, mild compressive residual stresses were found in the coating. According to Boruah et al. [9], this points towards the dominant effect of peening stresses originating from the constant bombarding of high velocity spray particles, which is compressive in nature. The quenching stresses arising from the contraction of individual cold sprayed splats as they rapidly cool down upon impact is supposed to generate some tensile stresses in the coating layer. However, the results imply the influence of thermal mismatch is negligible in our case in par with the analysis performed by Ghelichi et al. [24]. 


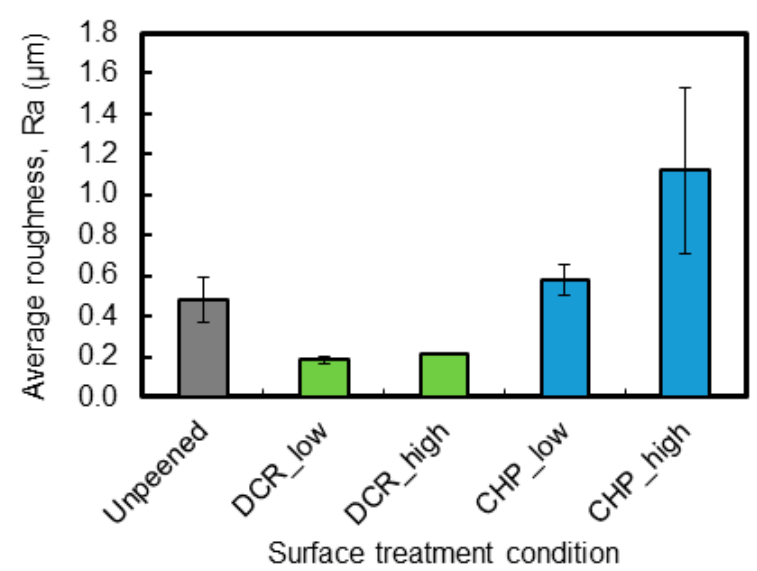

(a)

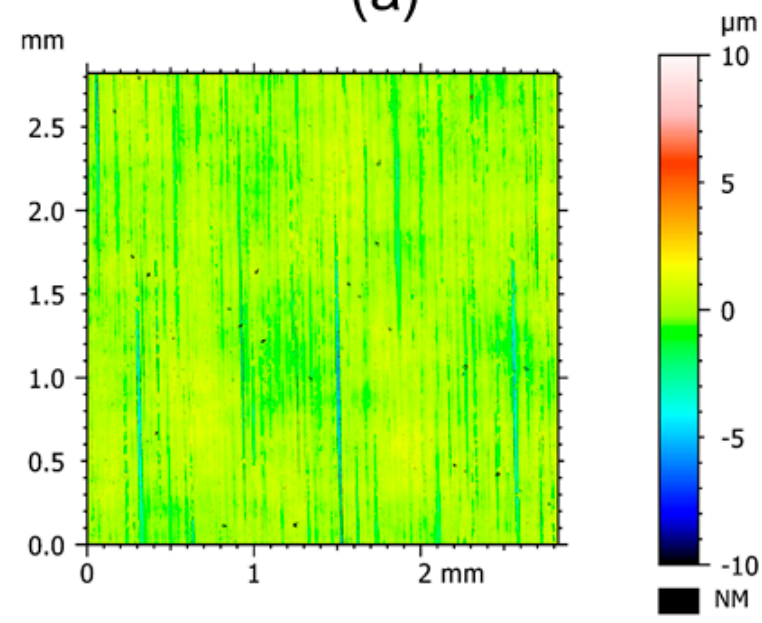

(c)

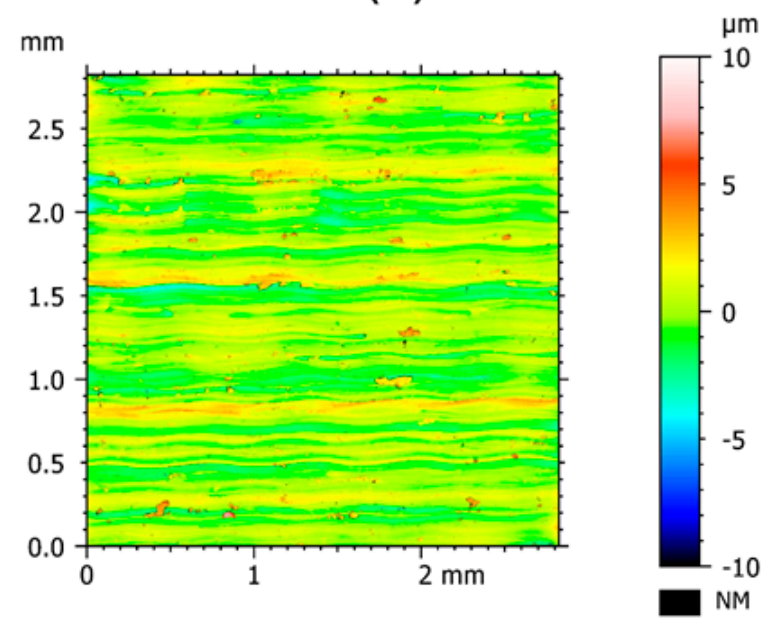

(e)

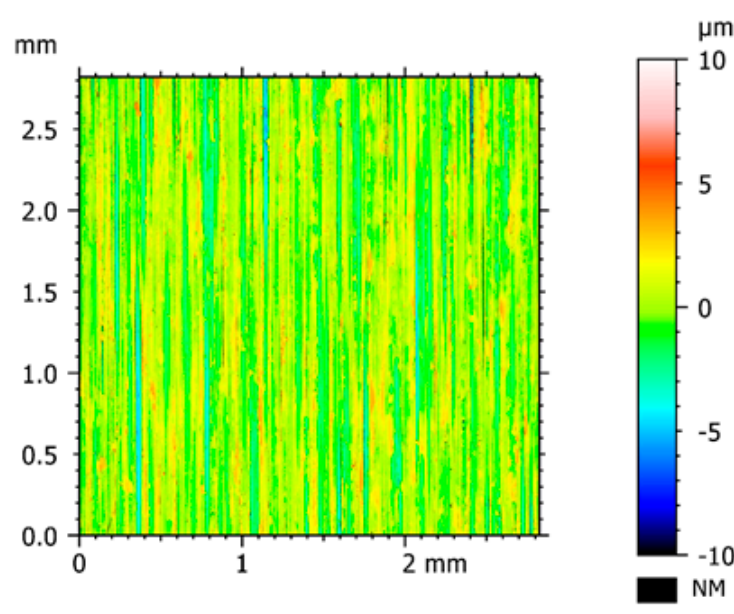

(b)

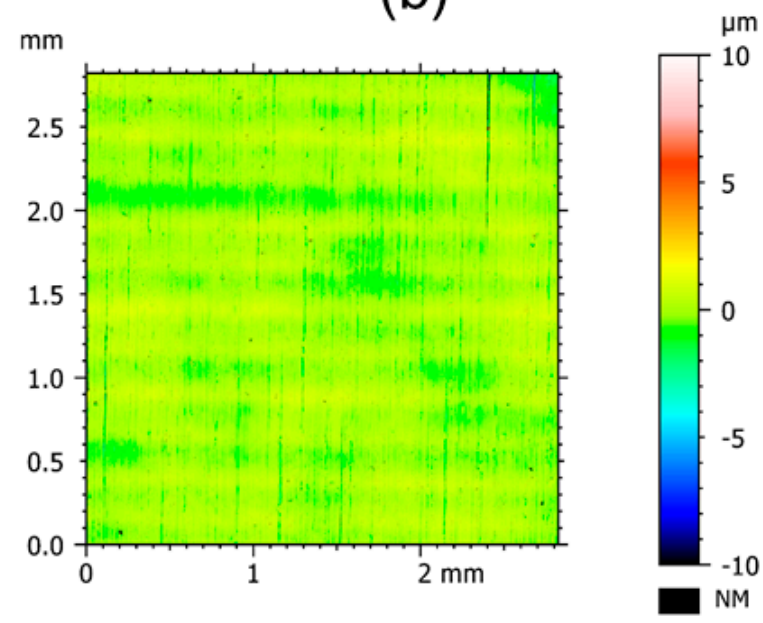

(d)

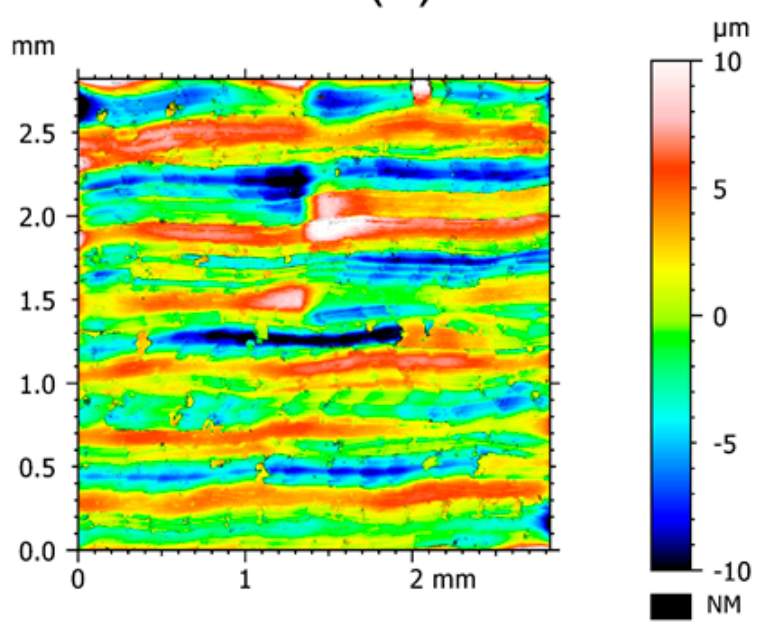

(f)

Figure 6. Surface maps under different conditions: (a) comparison of average roughness; (b) machined surface; (c) DCR at low pressure; (d) DCR at high pressure; (e) CHP under a low processing condition; (f) CHP under a high processing condition. 


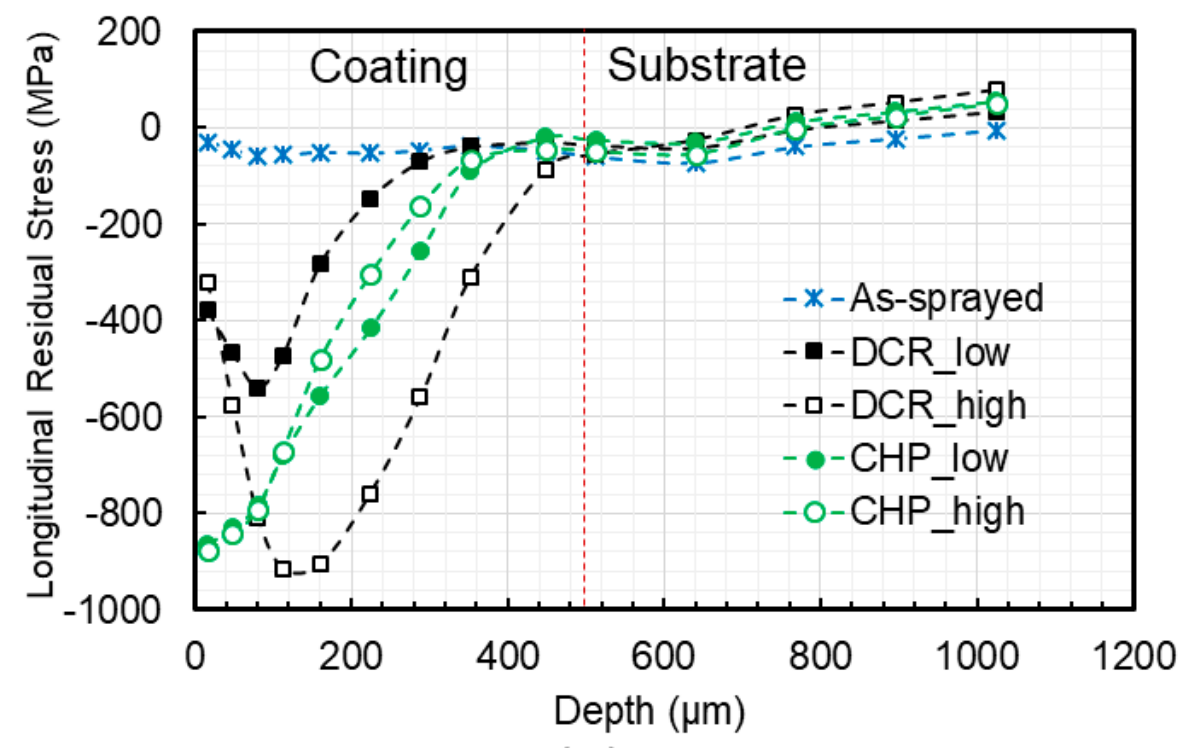

(a)

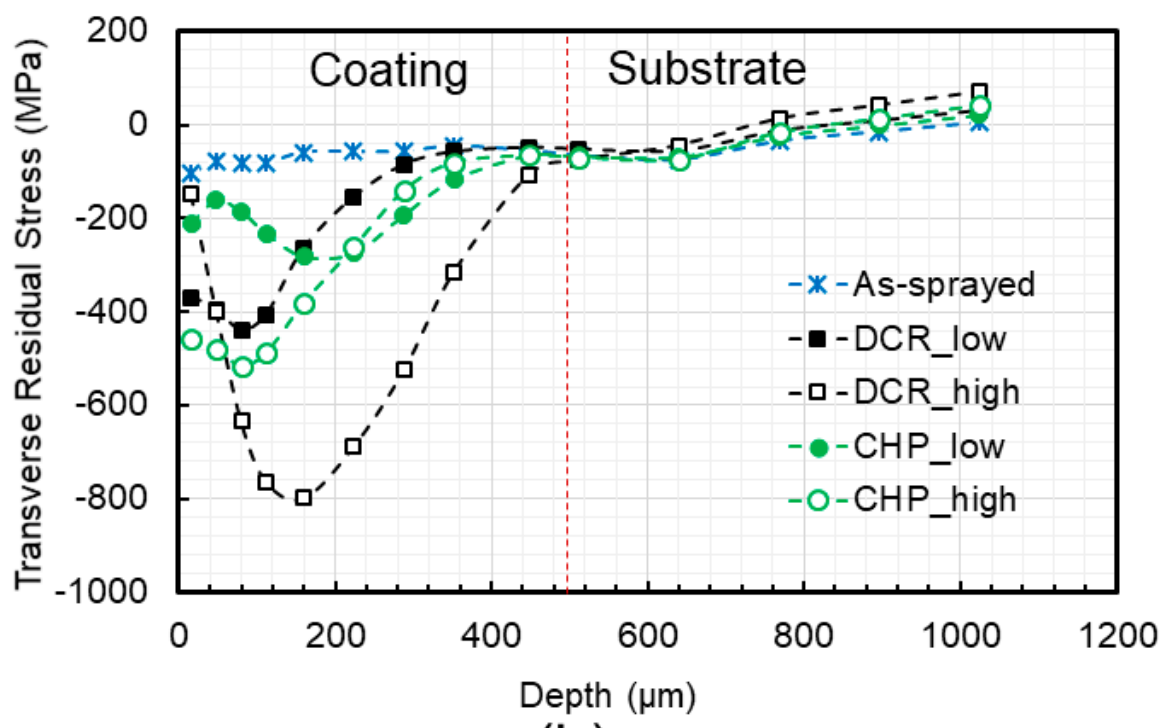

(b)

Figure 7. Residual stress profiles along the depth in the (a) longitudinal and (b) transverse direction.

Post-processing by both DCR and CHP resulted in high compressive residual stresses in the coating layer. A maximum compressive residual stress of about $900 \mathrm{MPa}$ was recorded for DCR under high pressure at the depth of $180 \mu \mathrm{m}$ from the surface. DCR under low pressure generated compressive residual stresses that were almost half in magnitude. Interestingly, CHP under low peening condition produced almost a similar compressive stress state as under a high peening condition in the longitudinal direction. Based on the current results, the reason for such behavior is unclear as it may be just a random error or affected by the initial condition of the material and peening parameters. Another interesting observation is that slightly higher residual stresses were measured in the longitudinal direction than in the transverse direction for all the cases. This was especially pronounced for CHP coupons, which demonstrates an anisotropic nature of the process.

Compared to the coating layer, the residual stresses induced in the substrate were quite low. One reason for such behavior is the decreasing influence of the surface peening 
along the depth. The peening effect followed the following sequence: DCR_low $<$ CHP_low $<$ CHP_high < DCR_high. The maximum depth of influence of about $500 \mu \mathrm{m}$ was achieved for DCR at high pressure. However, the depth of influence for DCR is known to extend to depths as deep as $1 \mathrm{~mm}$ from the surface [25]. The fact that the depth of influence at high pressure DCR is roughly equivalent to the thickness of the cold spray layer indicates that the peening effect must have been absorbed by the defects in the cold sprayed layer.

Furthermore, no distinct change was observed in the residual stress state at the coating substrate interface. This suggests that the interface does not show any effect on dictating the stress profile of a cold sprayed component during peening when the same material is used as a substrate and coating.

\subsubsection{Hardness}

Figure 8 compares the hardness profiles along the depth for coupons processed under different conditions. The substrate had a hardness of around $350 \mathrm{HV}$. The cold spray layer exhibited a higher hardness than that of the substrate for all cases. This can be attributed to the rapid plastic deformation that occurs during cold spraying. Post-processing by DCR and CHP did not alter the hardness values significantly. Furthermore, it is noteworthy to point out that the hardness data had a high degree of scatter. This was especially pronounced in the cold spray layer compared to that in the substrate. This could be due to the limitation in the measurement method itself. During the Vickers hardness test, the indent covers a large area including pores, the deformed region of cold spray splat and the inner undeformed core, which poses a challenge in accurately capturing the hardness of the coating. In addition, the presence of the heterogeneous microstructure and a large volume fraction of pores in the cold spray layer complicates the reading. Therefore, the values might fluctuate randomly depending on the location in the coupon. Interestingly, the hardness values did not change significantly after post processing indicating very little influence of DCR and CHP on the hardening mechanism.

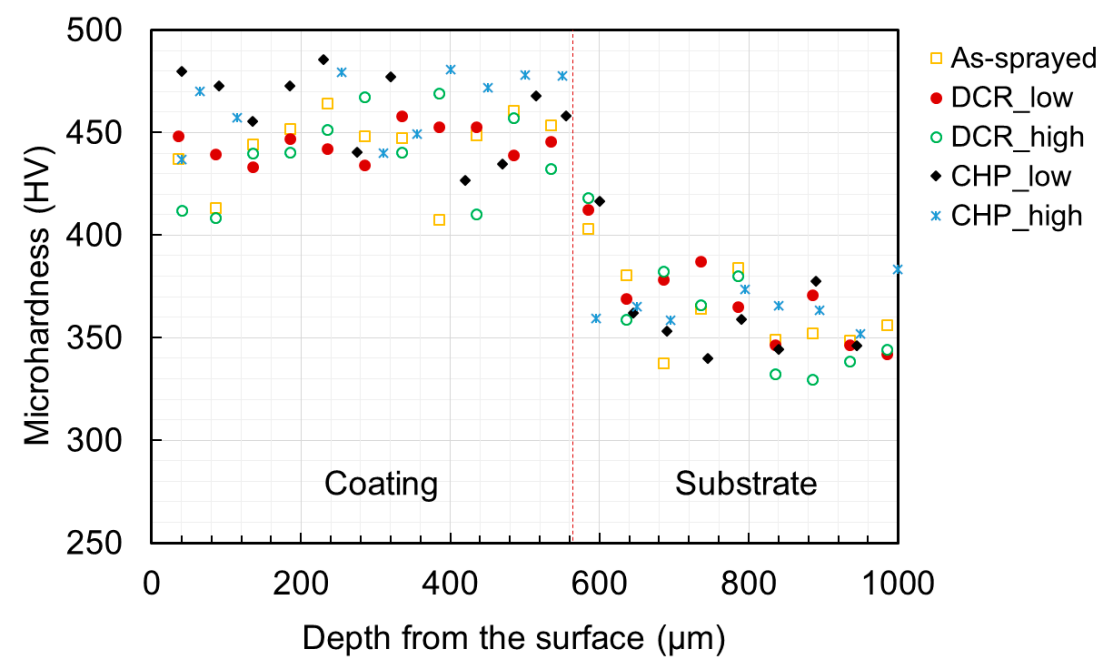

Figure 8. Graph showing variation in hardness along the depth.

\subsubsection{Porosity}

The as-sprayed coupons contain many pores as shown earlier in Figure 5. Postprocessing by DCR and CHP resulted in the reduction of the porosity by more than $50 \%$ in the cold spray coating. The results are shown in Figure 9. Processing at high peening conditions produced 1.2-1.5 times higher reduction in porosity than at low peening conditions. It is also interesting to note that CHP produced higher porosity reduction than DCR for the range of parameters used in this experiment. The maximum porosity reduction of almost $71 \%$ occurred for the coupon peened using $\mathrm{CHP}$ at high peening condition. 


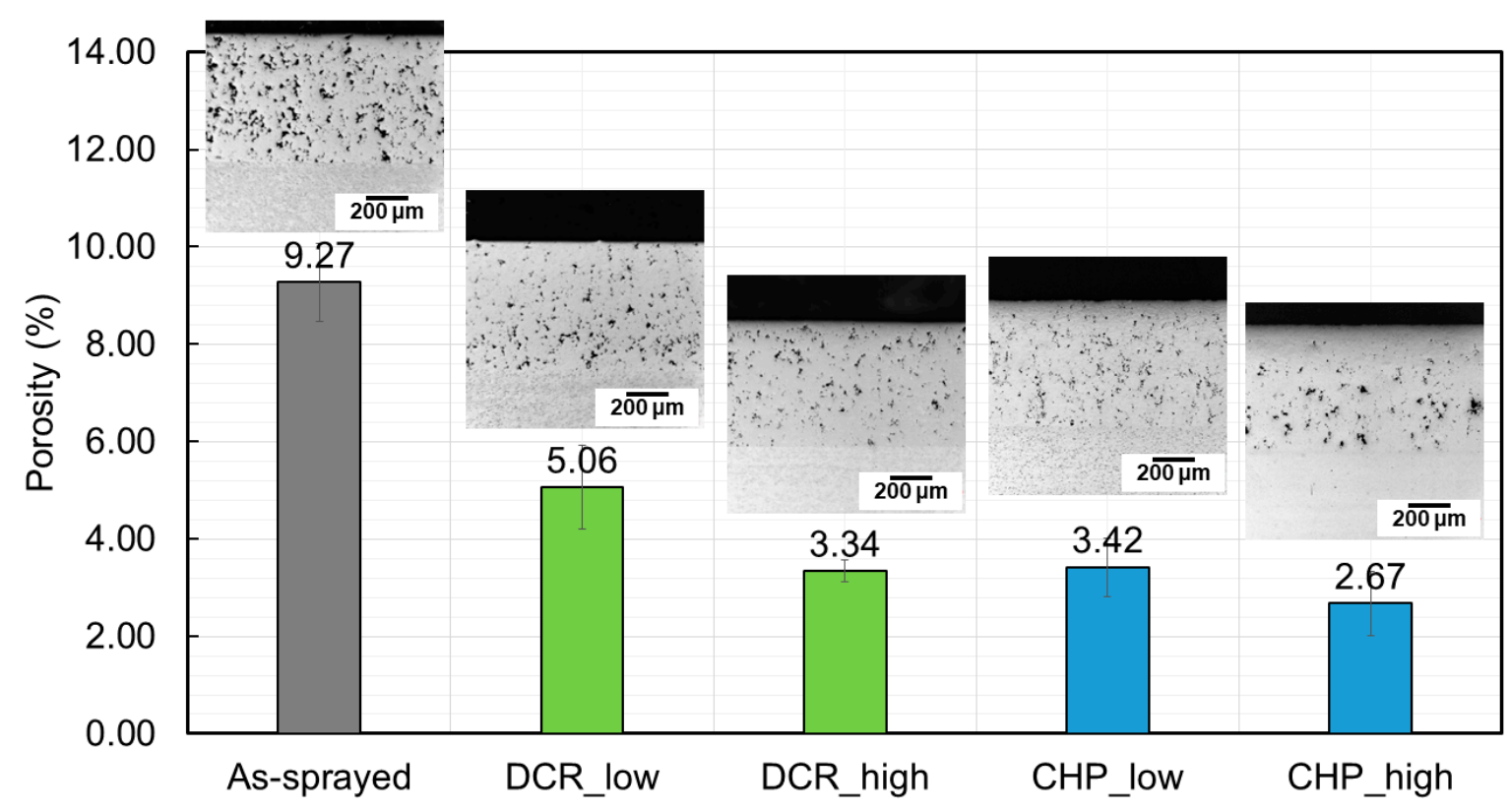

Figure 9. Porosity in coupons post-processed under various conditions.

One of the hypotheses for reduction in porosity during post-processing is due to the plastic deformation of the coating. In order to verify this, the thickness of the coating for each condition was measured (Figure 10). This was done by capturing the cross-section micrographs using an optical microscope. The results show that there was a reduction in the thickness of coating by approximately 10-20 $\mu \mathrm{m}$ after either DCR or CHP processing. This reveals that DCR and CHP has a compacting effect on the coating, which may be the mechanism of porosity reduction.

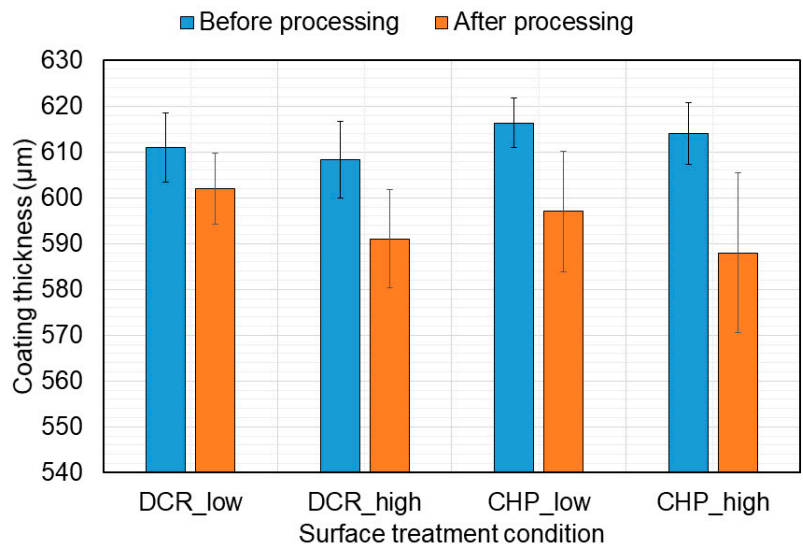

(a)

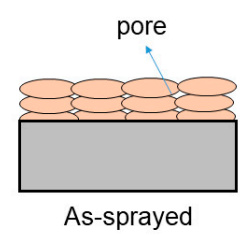

Coating compaction

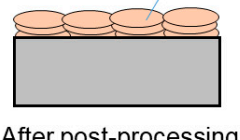

(b)

Figure 10. (a) Graph comparing the coating thickness of coupons treated under different conditions and (b) illustration of the compaction as a probable mechanism for porosity reduction.

\subsubsection{Bond Strength}

The results of bond strength measurements are tabulated in Table 4 . Failure for the as-sprayed coupon occurred at the coating-substrate interface and it exhibited a bond strength of $76( \pm 4) \mathrm{MPa}$. Post-processing by DCR improved the bond strength. For both high and low peening conditions of DCR, the bond strength exceeded the strength of the epoxy (>80 MPa). Therefore, absolute bond strength after DCR could not be determined 
from the experiment. Similarly, CHP also showed improvement in the bond strength of the coating. After the CHP processing, failure occurred at the epoxy in all the tests except for one coupon treated under the low CHP condition. This might be due to defects in the initial cold spray coating.

Table 4. Results of bond strength testing. I: Failure at the coating substrate interface. E: Failure at the epoxy.

\begin{tabular}{ccccc}
\hline & \multicolumn{3}{c}{ Failure Mode } & \\
\cline { 2 - 4 } Condition & $\mathbf{1}$ & $\mathbf{2}$ & $\mathbf{3}$ & Average Bond Strength (MPa) \\
\hline As-sprayed & I & I & I & $76 \pm 4$ \\
DCR_low & E & E & E & $>84$ \\
DCR_high & E & E & E & $>80$ \\
CHP_low & E & I & E & $>53$ \\
CHP_high & E & E & E & $>81$ \\
\hline
\end{tabular}

\section{Discussion}

High porosity and a weak bond strength of cold sprayed Ti-6Al-4V powder on the Ti-6Al-4V substrate threaten the structural integrity of cold sprayed component. Therefore, mechanical post-peening methods, DCR and CHP, were utilized to evaluate their effect on improving the coating adherence and hence the surface integrity. The results demonstrate that both peening processes are capable of reducing coating porosity and improving bond strength between the coating and the substrate.

When a cold spray particle impacts the substrate at supersonic speed, it undergoes significant plastic deformation. The plastic deformation is highly heterogeneous with most deformation occurring in the outer layer of the particle due to adiabatic shear instability [26]. The kinetic energy during impact is converted into heat, which is unable to dissipate in the short impact time leading to a dramatic rise in temperature at the periphery, which has been shown by finite element modeling [27]. The high impact strain produces a nanocrystalline $\alpha-\beta$ phase at the periphery and forms a strong bond with the substrate [28]. The impact strain duration is, however, not long enough to affect the entire cross-section of the splat. This results in the core region of the powder splats still remaining intact, i.e., consisting of parent martensitic $\alpha^{\prime}$ laths, even after the adherence process. Due to such heterogeneous plastic deformation, all powder particles cannot coalesce together and, hence, pores are formed in the cold spray layer.

The difference in the microstructure of the deformed and undeformed region can be clearly seen from the varying contrast within individual splat under the back-scattered SEM imaging mode (see Figure 11). A typical back-scattered image of the as-sprayed layer is shown in Figure 11a,b. According to Lek et al. [28], the light region indicates the deformed region that formed the refined nanocrystalline structure from the kinetic energy upon impact. The presence of such a deformed region improves bonding between cold spray particles. Large regions of non-bonded area exist in the as-sprayed condition between the substrate and powder and between powder layers. A clear lack of bonding at the centre of cold spray splat is shown in Figure 11b. Such poor bonding is attributed to the rebound effect from the impact [27] and lower temperature rise at the centre [7].

After post-processing with DCR and CHP, the volume fraction of the deformed region increased as seen qualitatively from the increase in the light textured region in Figure 11c-f. Furthermore, the pores and gap at the interface were also significantly reduced (Figure 9). This suggests that the compressive stresses and plastic deformation induced by the peening processes cause compaction of the coating and formation of the nanocrystalline phase, which increases its bond strength. 


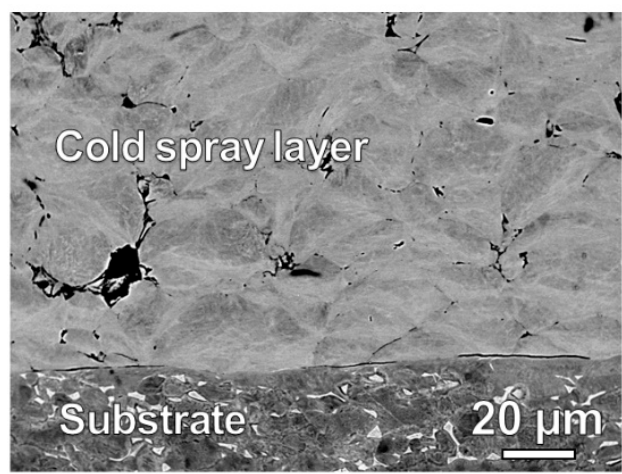

(a)

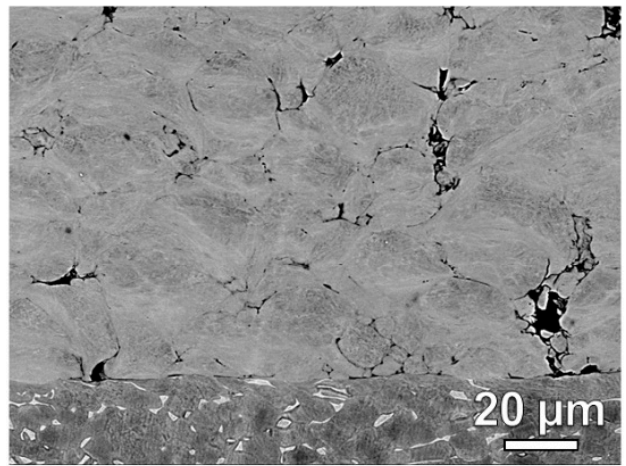

(c)

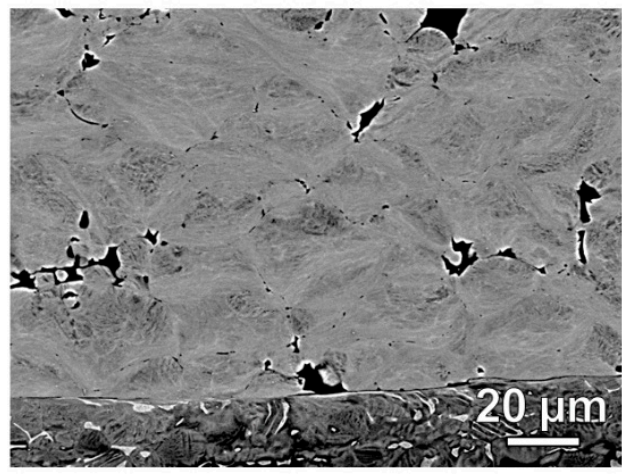

(e)

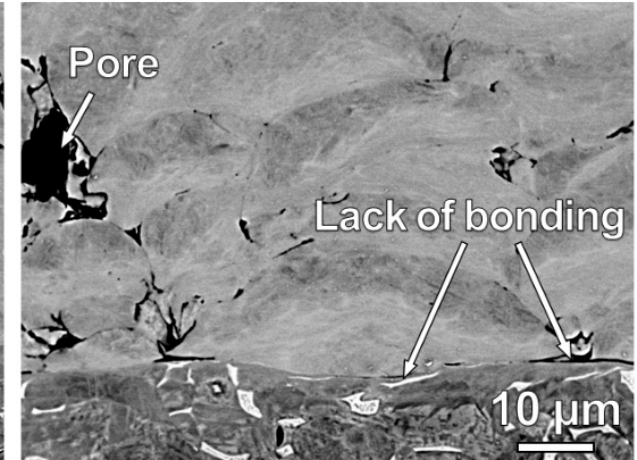

(b)

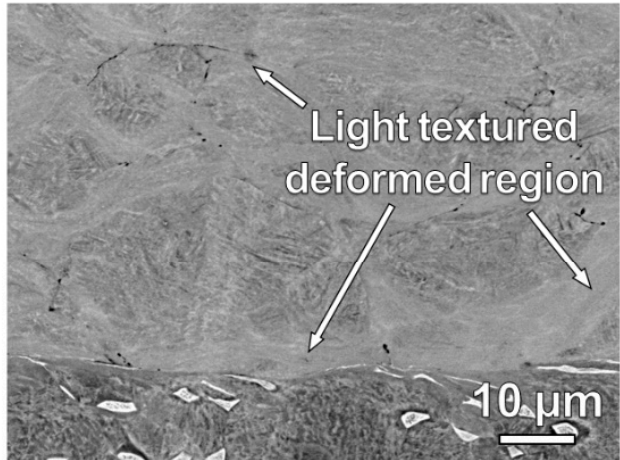

(d)

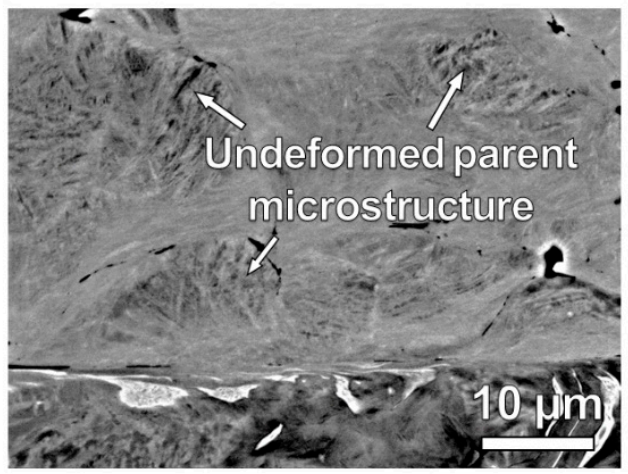

(f)

Figure 11. Backscattered SEM images of cold sprayed coupons in (a,b) as-sprayed; $(\mathbf{c}, \mathbf{d})$ deep cold rolled; (e,f) controlled hammer peened condition.

The change in the microscopic stresses induced post-peening was further determined by a peak shift from the samples during X-ray diffraction, as shown in Figure 12. For this analysis, the $\alpha^{\prime}$-[11-20] diffraction peak in high resolution was selected. Interestingly, a clear shift in the $2 \theta$ peak position is observed for the CHPed coupon compared to that of the as-sprayed condition. This suggests an introduction of greater microscopic stresses causing changes (shrinkage or dilation) in lattice planar spacing after CHP. However, there is only a minimal change in the diffracted peak position for the coupon after DCR compared to the as-sprayed condition. 


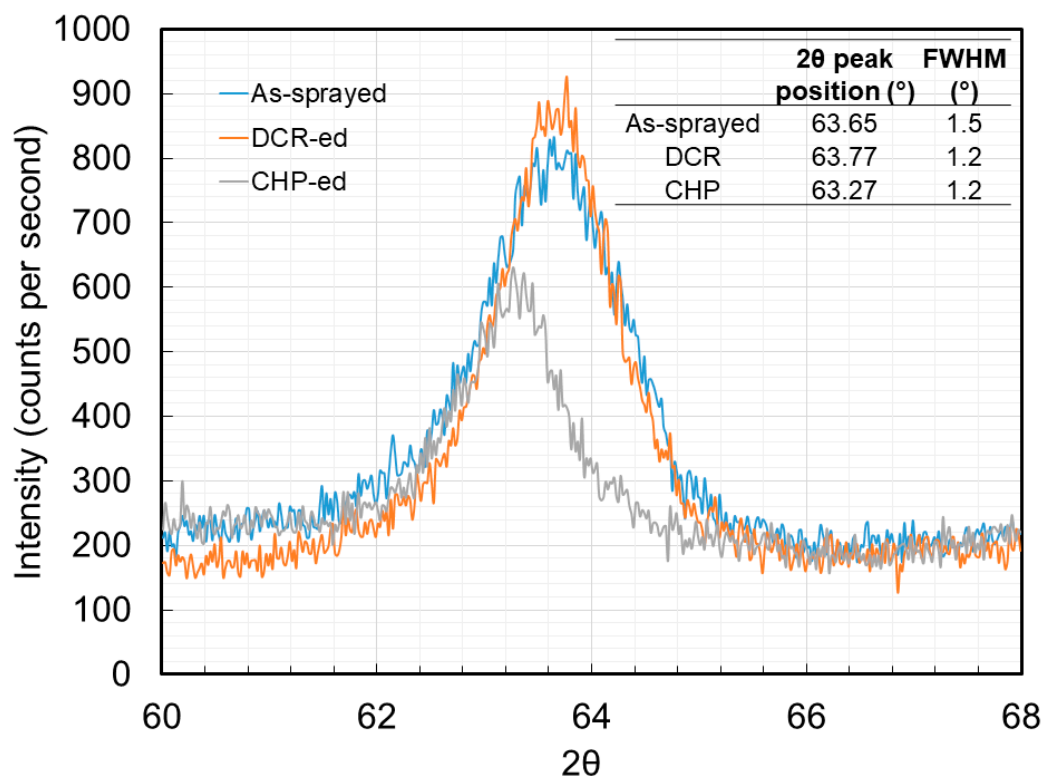

Figure 12. X-ray diffraction data showing a shift in peak position after post-processing.

The XRD data clearly shows that a greater degree of lattice strain is induced by CHP treatment to the as-sprayed coating. CHP is an impact based process in which the impact energy is provided by the kinetic energy of an oscillating tool. Hönnige et al. [29] and Kumar et al. [30] have shown that shock waves from CHP produces grain refinement in the component inducing microstresses near the surface. The CHP treatment resulted in a much higher degree of compaction (i.e., percentage reduction of the coating thickness after the treatment), as shown in Figure 10, of the sprayed coating (in comparison to DCR). This compaction effectively reduced the porosity and induced significant lattice strains. On the other hand, DCR is a contact based process in which a ball is pressed to the component under high pressure to generate plastic deformation by introducing Hertzian stresses. The Hertzian loading generates maximum compressive stresses at the sub-surface region and could only cause some reduction in porosity but no lattice strain in the Ti-6Al-4V coating.

The evidence of the improved coating-substrate bonding after peening can be observed from investigating the fracture surface as well. Figure 13 shows the difference between the substrate surface after removal of the cold spray layer for the as-sprayed and peened conditions. In both cases, the cold spray layer failed cohesively, which indicates the interface between the substrate and the coating had the weakest strength. Under the as-sprayed condition, some cold spray particles still adhered to the surface while in some cases particle pull-out was observed. More importantly, the impressions of the debonded particles on the surface were primarily circular-the centre of the circular impressions typically showed a faceted fracture while a ductile fracture occurred at the rims where bonding mainly was achieved [7]. The fractured surface shows the absence of strong bonding between cold spray particles and the substrate, wherein a significant fraction of the surface (flat surfaces) showed no particle impingement at all.

On the other hand, the fracture surface of the peened coupon (Figure 11b) was distinctly different from the as-sprayed fracture surface wherein it exhibited a much greater degree of ductile fracture. Clearly no circular impressions from particle debonding, as observed in the as-sprayed coating fractograph (Figure 11a) was observed. The fractured particles showed more elongated or non-spherical imprints. Although notable fraction of the area showed no particle bonding, the non-uniform particle fracture mostly exhibited ductile failure. This implies again a greater extent of particle adhesion caused by peening. The increased particle adhesion, as observed from the post-failure fracture surface, is responsible for increased coating-substrate bonding strength following peening. 


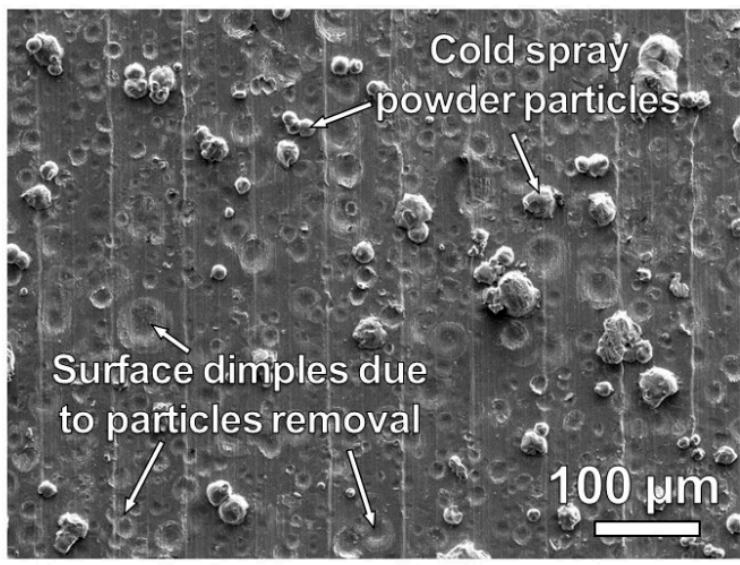

(a)

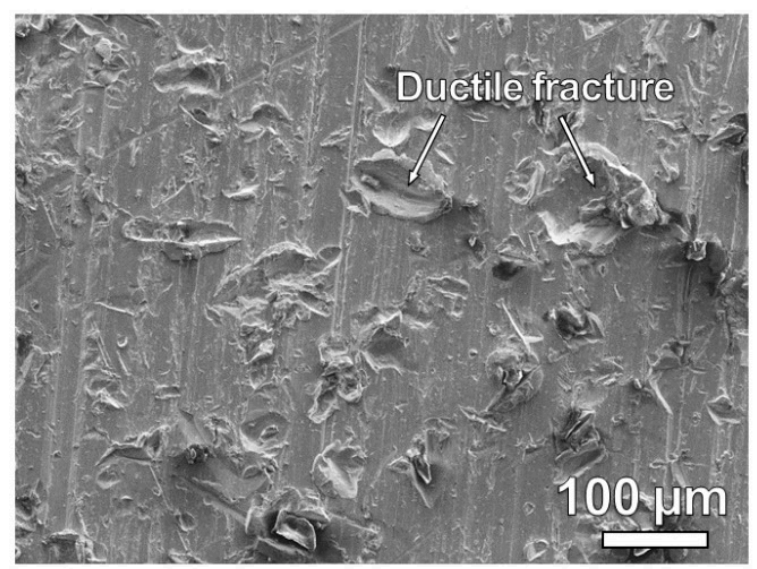

(b)

Figure 13. Fracture surface (substrate side) after the adhesive bond test for (a) as-sprayed and (b) post-peened conditions.

The study shows that peening processes are advantageous in reducing porosity and improving bond strength of the cold sprayed Ti-6Al-4V component. It is noteworthy to point out that the effect of peening could be observed in the whole of the cold spray layer for the current study as it had a thickness of only $0.6 \mathrm{~mm}$. However, repair of Ti-6Al$4 \mathrm{~V}$ components used in aircraft components often requires material build-up of several millimeters thickness. In such cases, the affected depth from mechanical peening might not cover the complete cold spray layer. A hybrid strategy combining cold spraying with intermittent mechanical peening after a few layers might be implemented in such a scenario. Nevertheless, the beneficial effects of peening treatments have been demonstrated in this study. Further studies are recommended to investigate the influence of mechanical peening on a thicker cold spray layer and on other metallic alloys.

\section{Conclusions}

The effect of post-processing by mechanical peening on the surface integrity of the cold sprayed Ti-6Al-4V alloy was investigated. Two mechanical peening processes, deep cold rolling (DCR), and controlled hammer peening (CHP), were explored to evaluate their capability to improve the quality of the cold spray coating and the bonding between the coating layer and the substrate. Based on the analysis, the following conclusions are made:

- $\quad$ Both DCR and CHP can reduce porosity and improve bond strength. Porosity reduced by as much as $71 \%$ and bond strength improved.

- DCR produced a smoother surface compared to the as-sprayed surface with an average roughness reducing from 0.5 to $0.2 \mu \mathrm{m}$. CHP resulted in an increase in surface roughness due to the formation of large dimples by the peening tool.

- The hardness of the cold spray coating was approximately $28 \%$ higher than that of the substrate. Mechanical peening did not bring a significant change in hardness.

- High compressive residual stresses were induced in the coating after DCR and CHP. Compressive stresses as high as $900 \mathrm{MPa}$ was recorded. CHP yielded significantly different compressive stresses in different directions (longitudinal and transverse) indicating its anisotropic nature. In addition, no particular difference in residual stresses was observed at the coating-substrate interface.

- $\quad$ CHP resulted in greater compaction and induction of lattice strains within the coating as compared to DCR.

- $\quad$ The increase in bond strength after post-processing is attributed to the compacting effect of the peening processes (reduced porosity) and to the greater degree of particle bonding with the substrate. 
Author Contributions: N.M.: Conceptualization, Methodology, Formal Analysis, Investigation, Data curation, Writing-Original Draft, Writing—Review and editing, Visualization; A.B.: Data analysis, Writing-Review and editing, Formal analysis; C.K.: Conceptualization, Data analysis, Manuscript revision; J.H.: Conceptualization, Methodology, Formal Analysis, Investigation; Y.Y.: Investigation, Data curation, Analysis; W.Z.: Supervision, Formal Analysis, validation, funding acquisition, writing-review and editing. All authors have read and agreed to the published version of the manuscript.

Funding: The funding for this study was provided by Advanced Remanufacturing and Technology Centre (ARTC), Singapore under Core Research Project Cycle 6 (CRP6-C19_01_ARTC).

Data Availability Statement: Not applicable.

Acknowledgments: The authors thank Boon Hee Tan and Qizhong Loi for their assistance in cold spray trials, and Jia Hui Lee for his help in overall project management. The authors are also grateful for the access to testing facilities at Materials Lab 1 (N3.2B2b-01) at Nanyang Technological University, Singapore.

Conflicts of Interest: The authors declare no conflict of interest. The funders had no role in the design of the study; in the collection, analyses, or interpretation of data; in the writing of the manuscript, or in the decision to publish the results.

\section{References}

1. Assadi, H.; Kreye, H.; Gärtner, F.; Klassen, T. Cold spraying-A materials perspective. Acta Mater. 2016, 116, 382-407. [CrossRef]

2. Yin, S.; Cavaliere, P.; Aldwell, B.; Jenkins, R.; Liao, H.; Li, W.; Lupoi, R. Cold spray additive manufacturing and repair: Fundamentals and applications. Addit. Manuf. 2018, 21, 628-650. [CrossRef]

3. Li, C.-J.; Li, W.-Y. Deposition characteristics of titanium coating in cold spraying. Surf. Coat. Technol. 2003, 167, 278-283. [CrossRef]

4. Li, W.; Cao, C.; Yin, S. Solid-state cold spraying of Ti and its alloys: A literature review. Prog. Mater. Sci. 2020, 110, 100633. [CrossRef]

5. Li, W.Y.; Zhang, C.; Guo, X.; Xu, J.; Li, C.J.; Liao, H.; Coddet, C.; Khor, K.A. Ti and Ti-6Al-4V coatings by cold spraying and microstructure modification by heat treatment. Adv. Eng. Mater. 2007. [CrossRef]

6. Vo, P.; Irissou, E.; Legoux, J.G.; Yue, S. Mechanical and microstructural characterization of cold-sprayed Ti-6Al-4V after heat treatment. J. Therm. Spray Technol. 2013, 22, 954-964. [CrossRef]

7. Tan, A.W.Y.; Sun, W.; Bhowmik, A.; Lek, J.Y.; Marinescu, I.; Li, F.; Khun, N.W.; Dong, Z.; Liu, E. Effect of coating thickness on microstructure, mechanical properties and fracture behaviour of cold sprayed Ti6Al4V coatings on Ti6Al4V substrates. Surf. Coat. Technol. 2018. [CrossRef]

8. Goldbaum, D.; Shockley, J.M.; Chromik, R.R.; Rezaeian, A.; Yue, S.; Legoux, J.G.; Irissou, E. The effect of deposition conditions on adhesion strength of Ti and Ti6Al4V cold spray splats. J. Therm. Spray Technol. 2012, 21, 288-303. [CrossRef]

9. Boruah, D.; Ahmad, B.; Lee, T.L.; Kabra, S.; Syed, A.K.; McNutt, P.; Doré, M.; Zhang, X. Evaluation of residual stresses induced by cold spraying of Ti-6Al-4V on Ti-6Al-4V substrates. Surf. Coat. Technol. 2019. [CrossRef]

10. Sun, W.; Tan, A.W.Y.; Khun, N.W.; Marinescu, I.; Liu, E. Effect of substrate surface condition on fatigue behavior of cold sprayed Ti6Al4V coatings. Surf. Coat. Technol. 2017, 320, 452-457. [CrossRef]

11. Adebiyi, D.I.; Popoola, A.P.; Botef, I. Experimental verification of statistically optimized parameters for low-pressure cold spray coating of titanium. Metals 2016, 6, 135. [CrossRef]

12. Zahiri, S.H.; Antonio, C.I.; Jahedi, M. Elimination of porosity in directly fabricated titanium via cold gas dynamic spraying. J. Mater. Process. Technol. 2009, 209, 922-929. [CrossRef]

13. Bhowmik, A.; Wei-Yee Tan, A.; Sun, W.; Wei, Z.; Marinescu, I.; Liu, E. On the heat-treatment induced evolution of residual stress and remarkable enhancement of adhesion strength of cold sprayed Ti-6Al-4V coatings. Results Mater. 2020. [CrossRef]

14. Astarita, A.; Rubino, F.; Carlone, P.; Ruggiero, A.; Leone, C.; Genna, S.; Merola, M.; Squillace, A. On the improvement of AA2024 wear properties through the deposition of a cold-sprayed titanium coating. Metals 2016, 6, 185. [CrossRef]

15. Nalla, R.K.; Altenberger, I.; Noster, U.; Liu, G.Y.; Scholtes, B.; Ritchie, R.O. On the influence of mechanical surface treatments-deep rolling and laser shock peening-on the fatigue behavior of Ti-6Al-4V at ambient and elevated temperatures. Mater. Sci. Eng. A 2003. [CrossRef]

16. Moridi, A.; Hassani-Gangaraj, S.M.; Vezzú, S.; Trško, L.; Guagliano, M. Fatigue behavior of cold spray coatings: The effect of conventional and severe shot peening as pre-/post-treatment. Surf. Coat. Technol. 2015. [CrossRef]

17. Luo, X.T.; Wei, Y.K.; Wang, Y.; Li, C.J. Microstructure and mechanical property of Ti and Ti6Al4V prepared by an in-situ shot peening assisted cold spraying. Mater. Des. 2015. [CrossRef]

18. Tan, A.W.-Y.; Sun, W.; Phang, Y.P.; Dai, M.; Marinescu, I.; Dong, Z.; Liu, E. Effects of traverse scanning speed of spray nozzle on the microstructure and mechanical properties of cold-sprayed Ti6Al4V coatings. J. Therm. Spray Technol. 2017, 26, 1484-1497. [CrossRef]

19. Grant, P.V.; Lord, J.D.; Whitehead, P. The Measurement of Residual Stresses by the Incremental Hole Drilling Technique. Meas. Good Pract. Guid. 2006, 53, 1-70. 
20. Marzbanrad, B.; Toyserkani, E.; Jahed, H. Customization of residual stress induced in cold spray printing. J. Mater. Process. Technol. 2020, 289, 116928. [CrossRef]

21. Kopsov, I.E. The influence of hammer peening on fatigue in high-strength steel. Int. J. Fatigue 1991, 13, 479-482. [CrossRef]

22. Zhuang, W.; Liu, Q.; Djugum, R.; Sharp, P.K.; Paradowska, A. Deep surface rolling for fatigue life enhancement of laser clad aircraft aluminium alloy. Appl. Surf. Sci. 2014, 320, 558-562. [CrossRef]

23. Oevermann, T.; Wegener, T.; Niendorf, T. On the evolution of residual stresses, microstructure and cyclic performance of high-manganese austenitic TWIP-steel after deep rolling. Metals 2019, 9, 825. [CrossRef]

24. Ghelichi, R.; Bagherifard, S.; Macdonald, D.; Fernandez-Pariente, I.; Jodoin, B.; Guagliano, M. Experimental and numerical study of residual stress evolution in cold spray coating. Appl. Surf. Sci. 2014. [CrossRef]

25. Wong, C.C.; Hartawan, A.; Teo, W.K. Deep cold rolling of features on aero-engine components. In Proceedings of the Procedia CIRP, 2nd CIRP Conference on Surface Integrity (CSI), Nottingham, UK, 28-30 May 2014.

26. Hussain, T. Cold Spraying of Titanium: A Review of Bonding Mechanisms, Microstructure and Properties. Key Eng. Mater. 2012. [CrossRef]

27. Song, X.; Everaerts, J.; Zhai, W.; Zheng, H.; Tan, A.W.Y.; Sun, W.; Li, F.; Marinescu, I.; Liu, E.; Korsunsky, A.M. Residual stresses in single particle splat of metal cold spray process-Numerical simulation and direct measurement. Mater. Lett. 2018. [CrossRef]

28. Lek, J.Y.; Bhowmik, A.; Tan, A.W.Y.; Sun, W.; Song, X.; Zhai, W.; Buenconsejo, P.J.; Li, F.; Liu, E.; Lam, Y.M.; et al. Understanding the microstructural evolution of cold sprayed Ti-6Al-4V coatings on Ti-6Al-4V substrates. Appl. Surf. Sci. 2018. [CrossRef]

29. Hönnige, J.R.; Davis, A.E.; Ho, A.; Kennedy, J.R.; Neto, L.; Prangnell, P.; Williams, S. The Effectiveness of Grain Refinement by Machine Hammer Peening in High Deposition Rate Wire-Arc AM Ti-6Al-4V. Metall. Mater. Trans. A Phys. Metall. Mater. Sci. 2020. [CrossRef]

30. Kumar, D.; Idapalapati, S.; Wang, W.; Narasimalu, S. Effect of surface mechanical treatments on the microstructure-propertyperformance of engineering alloys. Materials 2019, 12, 2503. [CrossRef] 